\section{"Qualidade de vida em irmãos de autistas" - II}

"Quality of life in siblings of autistic patients" - II

Sr. Editor,

A carta enviada sobre o artigo de minha autoria, "Quality of life in siblings of autistic patients", mostra uma compreensão e análise consistentes do tema abordado e dos aspectos relacionados a ele. As questões levantadas pelos autores da carta são pertinentes e gostaria de comentá-las.

Primeiramente, esclareço que este artigo versa sobre apenas um dos aspectos relacionados à avaliação da Qualidade de Vida (QV), avaliados na Dissertação de Mestrado "Qualidade de vida em irmãos de autistas", ${ }^{1}$ disponível para consulta na Biblioteca da Faculdade de Medicina da USP e também na do Instituto de Psiquiatria da mesma faculdade. Este aspecto, obtido através do Questionário da Qualidade de Vida Infantil $(A \cup Q U E I),{ }^{2}$ relaciona-se à opinião subjetiva das próprias crianças sobre sua QV.

É importante ainda ressaltar que o AUQUEI foi desenvolvido por pesquisadoras francesas e traduzido e validado para o português. ${ }^{3}$ Para sua maior compreensão, sugiro a consulta do artigo original, que esclarece o modo de desenvolvimento das perguntas na construção de tal questionário, ${ }^{2}$ além da leitura de um artigo anterior a este, no qual as autoras discorrem sobre 0 modo de colher o ponto de vista das crianças. ${ }^{4}$

Em minha Dissertação de Mestrado, está detalhada a seleção de sujeitos, incluindo o controle do viés citado sobre comorbidades (doenças físicas e/ou psiquiátricas), entre outros, garantindo amostras de crianças saudáveis. Além disso, houve controle de variáveis, como nível socioeconômico familiar, número de irmãos, responsáveis com quem vive, etc. A QV ainda foi avaliada de forma mais objetiva, através das Escalas de Comportamento Adaptativo de Vineland ${ }^{\circledR} .{ }^{5}$ Outros aspectos mais subjetivos, de difícil mensuração, como relações familiares, cuidado filial, continência parental, relações fraternas e outros, foram abordados tanto nos capítulos, quanto na discussão da Dissertação.

A escolha do grupo controle foi relacionada a um interesse no estudo de um aspecto específico da linguagem, incluído no transtorno específico de articulação da fala (TEAF), F 80.0, pela CID-10. Este transtorno foi escolhido por ser uma alteração de linguagem que perdura por longo período do desenvolvimento infantil, no qual o uso dos sons da fala pela criança está abaixo do nível apropriado para a idade mental, mas no qual há um nível normal de habilidade de linguagem. Ainda ressalto que o pareamento foi feito entre irmãos saudáveis de autistas e irmãos saudáveis de crianças com TEAF e não entre autistas e crianças com problemas de linguagem ou comunicação.

Por fim, agradeço o interesse em meu trabalho. Espero que trocas de idéias como essa ocorram mais vezes e coloco-me à disposição para esclarecimentos mais detalhados e troca de experiências. É só assim que, em longo prazo, obteremos mais benefícios aos nossos pacientes e seus familiares.

Adriana Regina Ferreira Marciano Instituto de Psiquiatria, Faculdade de Medicina, Universidade de São Paulo (USP), São Paulo (SP), Brasil

Financiamento: Inexistente

Conflito de interesses: Inexistente
Referências

1. Marciano ARF. Qualidade de Vida em irmãos de autistas. [tese] São Paulo: Faculdade de Medicina, Universidade de São Paulo: 2004.

2. Manificat S, Dazord A. Evaluation de la Qualité de Vie de l'enfant: validation d'un questionaire, premier résultats. Neuropsichiatr Enfance Adolesc. 1997;45(3):106-14.

3. Assumpção FB Jr, Kuczynski E, Sprovieri MH, Aranha EMG. Quality of life evaluation scale (AUQEI): validity and reability of a quality of life scale for children from 4 to 12 years. Arq Neuropsiquiatr. 2000;58(1):119-27

4. Manificat S, Dazord A, Cochat P, Nicolas J. Evaluation de la Qualité de Vie en pediatrie: comment recueillir le point de vue de l'enfant. Arch Pédiatr. 1997;4:1238-46.

5. Sparrow SS, Balla DA, Cicchetti DV. Vineland Adaptative Behavior Scales. Interview Edition - Survey Form. Circle Pines (MN): American Guidance Service; 1984.

\section{Topiramato reduz irritabilidade e automutilação em crianças autistas}

Topiramate reduces irritability and self-injuries in autistic children

\section{Sr. Editor}

O topiramato foi inicialmente introduzido para o tratamento da epilepsia. ${ }^{1}$ No entanto, com o tempo, foram surgindo outras indicações para o seu uso psiquiátrico, tais como o comer compulsivo ou a agressividade/irritabilidade em pacientes com transtornos mentais devidos a disfunções cerebrais: demência, ${ }^{2}$ retardo mental, ${ }^{3}$ síndrome de Willi-Prader. ${ }^{4}$ Outros pacientes com doenças psiquiátricas funcionais, como transtorno de personalidade tipo borderline, também parecem beneficiar-se de sua ação "anti-irritabilidade". ${ }^{5}$ No autismo, o único estudo realizado com topiramato foi feito na tentativa de reduzir o ganho ponderal induzido por neurolépticos. ${ }^{6}$ Pacientes com transtorno invasivo do desenvolvimento podem exibir comportamentos automutilatórios, clásticos, com grande irritabilidade.

Esses casos são, geralmente, refratários às diversas medicações disponíveis. A seguir, resumimos o caso de uma dessas crianças. Caso Clínico: M., 9 anos de idade, é um garoto autista que está internado para o tratamento de gravíssimas automutilações: bate a cabeça nas pontas das mesas, nas paredes, dá murros nos olhos, nas orelhas, desenvolvendo hemorragias oculares, otorragias, otohematomas, fratura de mastóide, oreIha pugilística, descolamento de retina, odontoextração. Tem uma grande irritabilidade, grita muito, uma importante agitação motora. Fez uso das seguintes medicações, sem sucesso, em doses adequadas e por um tempo correto: clorpromazina (chegou a $800 \mathrm{mg} / \mathrm{dia}$, usou a medicação por aproximadamente nove meses, entre a introdução e a dose final de $800 \mathrm{mg} / \mathrm{d}$ ), diazepam (até $70 \mathrm{mg} / \mathrm{dia}$, aproximadamente por quatro meses), haloperidol (até $50 \mathrm{mg} / \mathrm{dia}$, por três meses), naltrexone (até $150 \mathrm{mg} / \mathrm{dia}$, por três meses), levomepromazina (200 mg/dia, por um mês), carbamazepina (até $600 \mathrm{mg} / \mathrm{dia}$, por dois meses), carbonato de lítio (900 mg/dia, por dois meses), citalopram (até $40 \mathrm{mg} / \mathrm{dia}$, por três meses), fluoxetina (até $60 \mathrm{mg} / \mathrm{dia}$, por 45 dias), valproato de sódio (1,2 g, por dois meses), propranolol (até $440 \mathrm{mg} / \mathrm{dia}$, por seis meses), buspirona (até $20 \mathrm{mg} / \mathrm{dia}$, por três meses), trazodona (125 mg/dia, por 45 dias). Algumas destas medicações foram utilizadas em conjunto com outras. De todas elas, a única que produziu um alívio temporário (aproximadamente sete meses) e parcial dos sintomas, foi a clorpromazina e, em menor 